Rayleigh Number

M. Vancoppenolle et al.

\title{
Technical Note: On the use of the mushy-layer Rayleigh number for the interpretation of sea-ice-core data
}

M. Vancoppenolle ${ }^{1}$, D. Notz ${ }^{2}$, F. Vivier ${ }^{1}$, J. Tison $^{3}$, B. Delille ${ }^{4}$, G. Carnat ${ }^{3}$, J. Zhou ${ }^{3}$, F. Jardon ${ }^{1}$, P. Griewank ${ }^{2}$, A. Lourenço ${ }^{1}$, and T. Haskell ${ }^{5}$

${ }^{1}$ LOCEAN - Laboratoire d'Océanographie et du Climat (CNRS, IRD, UPMC, MNHN), UMR7159, IPSL, Paris, France

${ }^{2}$ Max Planck Institute for Meteorology, Hamburg, Germany

${ }^{3}$ Université Libre de Bruxelles, Belgium

${ }^{4}$ Université de Liège, Belgium

${ }^{5}$ Callaghan Innovation Research Ltd, Wellington, New Zealand

Title Page

Received: 17 June 2013 - Accepted: 26 June 2013 - Published: 1 July 2013

Correspondence to: M. Vancoppenolle (martin.vancoppenolle @locean-ipsl.upmc.fr)

Published by Copernicus Publications on behalf of the European Geosciences Union.

Abstract

Introduction

Conclusions

References

Tables

Figures

14

$\Delta \mathbf{I}$

4

Back

Close

Full Screen / Esc

Printer-friendly Version

Interactive Discussion

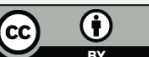




\section{Abstract}

We examine some practical aspects of using a mushy-layer Rayleigh number for the interpretation of sea-ice-core data. In principle, such analysis should allow one to determine convectively active regions within the ice core by identifying those regions in

5 which the mush-Rayleigh number is super-critical. In practice, however, a quantitative analysis is complicated by uncertainties regarding the specific formulation of both the mush-Rayleigh number itself and of the sea-ice permeability that is crucial for quantifying the Rayleigh number. Additionally, brine loss from highly permeable sections of the ice core, in particular close to the ice-ocean interface, and typically weekly ice core sampling, limit the practical applicability of the Rayleigh number for ice-core interpretation. We here quantify these uncertainties, suggest a standard method for the computation of the Rayleigh number for sea ice and discuss possibilities and limitations of ice-core interpretation based on the Rayleigh number.

\section{Introduction}

15 Brine convection desalinates sea ice (Untersteiner, 1968; Notz and Worster, 2009) and drives the exchange of biogeochemical tracers between sea ice and the underlying sea water (e.g. Thomas and Dieckmann, 2010). The convection is driven by the density difference between high-salinity brine in the ice and the sea water underneath. Its onset and strength can be described by a mushy-layer Rayleigh number of the form

$20 \quad R a=\frac{g \Delta \rho z \Pi}{\kappa \mu}$.

Here, $g$ is gravity, $\Delta \rho$ is the density difference between the brine and the sea water, $z$ is the vertical distance between the brine and the sea water, $k$ is thermal diffusivity, $\mu$ is dynamic viscosity and $\Pi$ is permeability. The Rayleigh number can be interpreted in two ways. One could think of it as being a ratio of the two time scales that govern
Rayleigh Number

M. Vancoppenolle et al.

Title Page

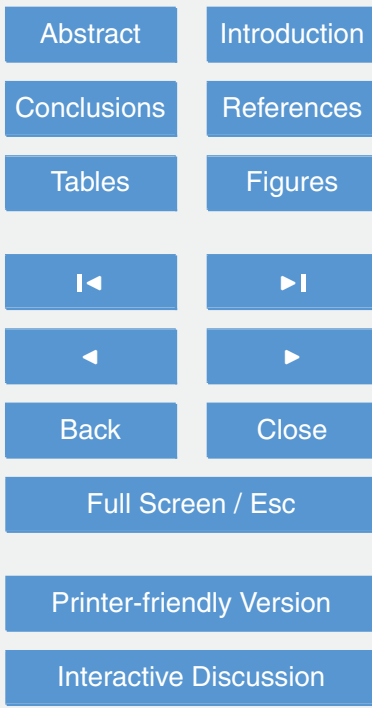

Interactive Discussion 
convection: a diffusive time scale $z^{2} / \kappa$ and an advective time scale $z \mu /(g \Delta \rho \Pi)$ as determined from Darcy's law with $g \Delta \rho$ as the driving pressure gradient. If the diffusive time scale is shorter than the advective time scale, brine temperature, and hence, because of the required phase equilibrium, its salt content, will adjust to the surround5 ing ice; convection stops. The Rayleigh number can also be interpreted as the ratio of the potential energy density $g \Delta \rho z$ available for convection and the energy density $\kappa \mu / \Pi$ that is dissipated during convection through thermal diffusion and internal friction because of the brine's viscosity.

In situ measurements of the salinity evolution of sea ice reveal that indeed, this evolution can be understood by an analysis of the according mush-Rayleigh number: as long as that number is super-critical, the bulk salinity of the ice decreases, once the number becomes sub-critical, the bulk salinity no longer changes. The Rayleigh number is particularly large in the highly permeable region close to the ice interface during ice growth, causing efficient desalination there (Notz and Worster, 2008). Recently the relationship of the mushy-layer Rayleigh number to brine flux has been theoretically studied, using idealized 2-D numerical simulations (Wells et al., 2010) as well as 2-D and 3-D analytical approaches (Rees Jones and Worster, 2013b). Results from these studies were successfully applied to explain salt loss and the convection depth in synthetic sea ice (Wells et al., 2011; Rees Jones and Worster, 2013a).

20 During the spring transition, the warming induced increase in sea-ice permeability can render the Rayleigh number super-critical throughout the entire thickness of the ice, causing full-depth desalination of the ice and its replenishment with nutrients as suggested by model studies (Vancoppenolle et al., 2010; Jardon et al., 2013; Griewank and Notz, 2013). Hence, $R a$ is a powerful indicator of brine convection that could in principle be very helpful for the interpretation of ice-core data: the sample-depending quantities $\Delta \rho$ and $\Pi$ depend directly on temperature $(T)$ and bulk salinity $(S)$, which are the two standard variables that are commonly obtained in ice-core studies. Indeed, ice core derived $R a$ has been provided as a component of the physical context in recent biogeochemical sea ice studies (see, e.g. Carnat et al., 2013; Zhou et al., 2013).

Rayleigh Number

M. Vancoppenolle et al.

Title Page

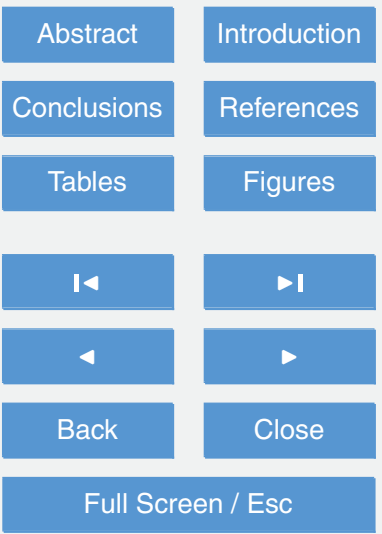

Printer-friendly Version

Interactive Discussion 
However, the interpretation of $R$ a derived in this manner is not straightforward, because the physical quantities involved in the computation have several possible expressions and because of observational errors in ice core $S$ and $T$. Hence, conclusions based on the comparison of $R$ a to a specific threshold value can be misleading.

5 In the following section, we will describe some of the uncertainties regarding the calculation of the mush Rayleigh number from ice-core data. In Sect. 3, we detail how these uncertainties affect the Rayleigh number computations. In Sect. 4, we briefly discuss the possible impact of sampling errors. Based on these analyses, we provide some guidance on a possible best-practice for the interpretation of ice-core data based on a Rayleigh number in the concluding Sect. 5.

\section{Uncertainties in the calculation of the Rayleigh number}

Apart from the gravitational acceleration $g=9.81 \mathrm{~ms}^{-2}$, different approaches have been used for all input parameters that go into the calculation of $R a$ according to Eq. (1). We discuss each of these individually.

\subsection{Density difference $\Delta \rho$}

For the calculation of the density difference between the brine and the underlying sea water obviously the density of both must be known. For the density of sea water, the most precise results are obtained by using the full equation of state of sea water in its most modern formulation TEOS-10 (IOC, SCOR and IAPSO, 2010). For brine, no equally precise method for calculation of its density currently exists for the entire temperature range that is experienced in natural sea ice, primarily due to a lack of sufficiently precise measurements at low temperatures and the accordingly high brine salinity. A Gibbs function, which forms the foundation of modern methods to calculate the equation of state of sea water, was defined down to a temperature of $-6^{\circ} \mathrm{C}$ and up
Rayleigh Number

M. Vancoppenolle et al.

Title Page

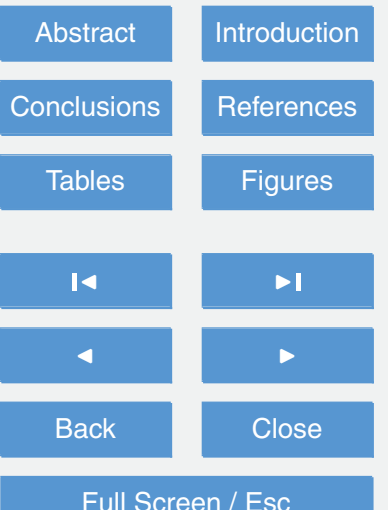

Full Screen / Esc

Printer-friendly Version

Interactive Discussion 
differences can be carried out with a high degree of accuracy, using the numerical packages that can be downloaded from the TEOS-10 website (e.g. McDougall and Barker, 2011).

For simplicity, the density difference between brine and sea water $\Delta \rho=\rho_{\mathrm{br}}-\rho_{\mathrm{oc}}$ often 5 assumes that brine density linearly depends on the brine-sea water salinity difference, e.g.,

$\rho_{\mathrm{br}}=\rho_{\mathrm{oc}}\left[1+\beta\left(S_{\mathrm{br}}-S_{\mathrm{oc}}\right)\right]$,

with $\beta$ the haline contraction coefficient and $\rho_{\mathrm{oc}}$ the sea water density with a salinity $S_{\mathrm{oc}}$ and a temperature equal to the freezing point. Defining $B=\rho_{\mathrm{oc}} \beta$, we get

$\Delta \rho=B\left(S_{\mathrm{br}}-S_{\mathrm{oc}}\right)$.

Sea water with $S_{\mathrm{oc}}=34 \mathrm{~g} \mathrm{~kg}^{-1}$ and at its freezing point $\left(-1.85^{\circ} \mathrm{C}\right)$ is, following TEOS-10, characterized by $\beta=0.79 \times 10^{-4} \mathrm{kgg}^{-1}, \rho_{\mathrm{oc}}=1027 \mathrm{kgm}^{-3}$ and $B=$ $0.81 \mathrm{~kg} \mathrm{~m}^{-3}\left(\mathrm{~g} \mathrm{~kg}^{-1}\right)^{-1}$. The actual TEOS-10 density difference for brine at $-6^{\circ} \mathrm{C}$ with a salinity of $\sim 100 \mathrm{~g} \mathrm{~kg}^{-1}$ compared to such sea water is $52.3 \mathrm{~kg} \mathrm{~m}^{-3}$, whereas the linear relation gives $53.4 \mathrm{~kg} \mathrm{~m}^{-3}$, e.g., a $2 \%$ difference. Since uncertainties in other parameters are usually much larger, for practical purposes, using this constant $B$ gives sufficiently reliable results. At lower temperatures and higher salinities, the calculations cannot be performed, because the TEOS-10 fit is not well-behaved.

Formulation (3) requires the brine salinity to be known. This can be derived from measurements of ice-core temperature, since the brine salinity is practically in phase equilibrium with the in-situ temperature. A fit to experimental data by Assur (1958) is given by Notz (2005):

$S_{\mathrm{br}}=-1.2-21.8 T-0.919 T^{2}-0.0178 T^{3}$.

However, often a simpler, linear relationship between brine salinity and in-situ temper- ature is used based on the linearised freezing point relationship of sea water, namely 3213

7, 3209-3230, 2013

Rayleigh Number

M. Vancoppenolle et al.

Title Page

Abstract

Conclusions

Tables

14

4

Back

Full Screen / Esc

Printer-friendly Version

Interactive Discussion
References

Figures

$\Delta \mathbf{I}$

$\triangleright$

Close 
with $\alpha=0.054^{\circ} \mathrm{C}\left(\mathrm{g} \mathrm{kg}^{-1}\right)^{-1}$. This gives significantly different results compared to the third-order fit from $-5{ }^{\circ} \mathrm{C}$ towards low $T$ 's, reaching nearly a $100 \mathrm{~g} \mathrm{~kg}^{-1}$ difference at $5-15^{\circ} \mathrm{C}$ (see Fig. 1a). Hence, especially for cold sea ice, the full third order polynomial should be used.

\subsection{Permeability $\Pi$}

For the calculation of permeability $\Pi$, the porosity must be known. Neglecting the gas content of sea ice, the porosity reduces to brine volume fraction $e$ (or liquid fraction) and can be calculated from known bulk salinity and brine salinity according to

$e=\frac{r S}{S_{\mathrm{br}}+S(r-1)}$

(Notz, 2005). Here, $r=\rho_{\mathrm{i}} / \rho_{\mathrm{br}}$ is the pure ice-brine density ratio. Pure ice density can be approximated as $\rho_{\mathrm{i}}=916.8-0.1403 T$, where $T$ is in degree centigrade (Pounder, 1965), and brine density is estimated using Eq. (2). Assuming a linear brine freezing point and $r=1$, liquid fraction reduces to:

$$
\begin{aligned}
e & \approx S / S_{\mathrm{br}} \\
& \approx-\alpha S / T,
\end{aligned}
$$

which only slightly overestimates Eq. (6) (see Fig. 1b) by a mean absolute difference of $\Delta e=0.77 \%$ over the -15 to $0{ }^{\circ} \mathrm{C}$ range.

20 The relation between $\Pi$ and porosity typically neglects gas content, thus the total porosity reduces to $e$. The dependence of permeability on porosity is not well constrained; two parameterizations are most widely used. Based on laboratory and field experiments, Freitag (1999) proposes

$\Pi=1.995 \times 10^{-8} \cdot e^{3.1}$.

Rayleigh Number

M. Vancoppenolle et al.

Title Page

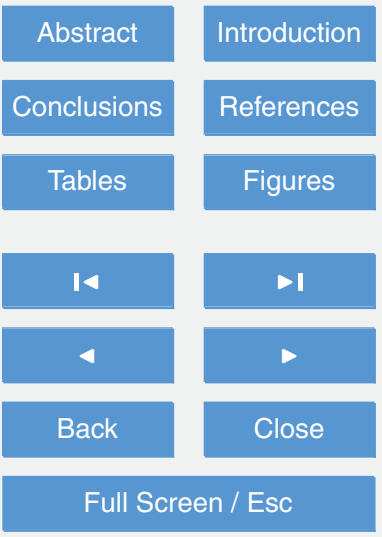

Printer-friendly Version

Interactive Discussion

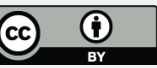


Based on measurements in first-year Arctic sea ice, Eicken et al. (2004) suggest

$\Pi= \begin{cases}4.708 \times 10^{-14} \cdot \exp (76.90 e), & e \leq 0.096 \\ 3.738 \times 10^{-11} \cdot \exp (7.265 e), & e>0.096\end{cases}$

This gives values of $\Pi$ that are up to one order of magnitude larger than the estimate 5 by Freitag (1999) (see Fig. 1c) for brine volumes between 5 and $20 \%$. For both formulations, a marked permeability increase occurs near $e=5 \%$, representing the increase in brine connectivity (Golden et al., 1998, see dotted line in Fig. 1c).

To calculate the Rayleigh number for a certain level in the ice, ideally the harmonic mean of the permeability of all ice between that level and the ice-ocean interface is calculated. However, for practical purposes, usually simply the minimum permeability of the ice between a specific level and the ice-ocean interface is used as the deciding value of $\Pi$.

\subsection{Vertical distance $z$}

Early formulations of the mushy-Rayleigh number simply used the ice thickness as the vertical distance $z$ (e.g. Wettlaufer et al., 1997). To account for vertical variability of the mush Rayleigh number, Notz and Worster (2008) introduced a depth dependent Rayleigh number, where $z$ is given as the distance from a specific level in the ice to the ice-ocean interface.

\subsection{Thermal diffusivity $\kappa$}

20 The choice of the correct value for the thermal diffusivity $k$ is subject to physical interpretation. Notz and Worster (2008) use the thermal diffusivity of cold sea water $k=1.2 \times 10^{-7} \mathrm{~m}^{2} \mathrm{~s}^{-1}$, calculated from a heat conductivity $k=0.5 \mathrm{~W}(\mathrm{Km})^{-1}$, a heat ca-

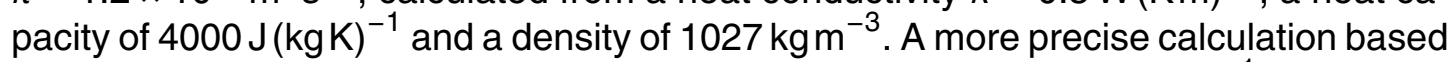
on the equations given in Sharqawy et al. (2010) gives $k=0.55 \mathrm{~W}(\mathrm{Km})^{-1}$ and hence ${ }_{25} k=1.3 \times 10^{-7} \mathrm{~m}^{2} \mathrm{~s}^{-1}$ for sea water at $0^{\circ} \mathrm{C}$ and $34 \mathrm{~g} \mathrm{~kg}^{-1}$. A somewhat higher value of

Rayleigh Number

M. Vancoppenolle et al.

Title Page

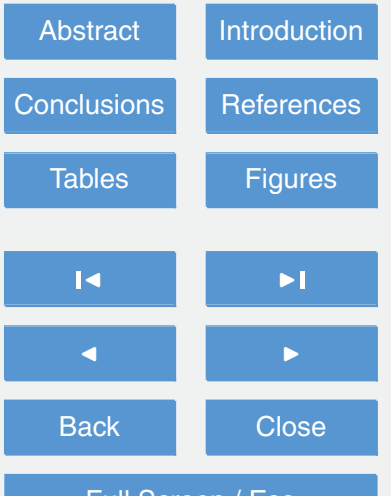

Full Screen / Esc

Printer-friendly Version

Interactive Discussion 
$\kappa=1.4 \times 10^{-7} \mathrm{~m}^{2} \mathrm{~s}^{-1}$ is obtained for sea water at $0^{\circ} \mathrm{C}$ and $100 \mathrm{~g} \mathrm{~kg}^{-1}$. For brine at lower temperature, only very little data is available to allow for a calculation of $k$. In particular, precise measurements of heat conductivity are largely lacking. The choice of a thermal diffusivity as representative for interstitial brine is based on the assumption that the 5 controlling process for the exchange of heat between brine and the surrounding ice is the temperature adjustment of the small mass of the moving brine as it moves through the ice (see Griewank and Notz, 2013, for discussion).

Based on the interpretation that $R$ a compares the time scales of vertical brine motion to those associated with heat diffusion in sea ice, where sea ice always maintains phase equilibrium with the moving brine, the thermal diffusivity of sea ice is used in the LIM1D model (Vancoppenolle et al., 2010). This thermal diffusivity includes a constant sea ice density $\left(\rho=917 \mathrm{kgm}^{-3}\right)$, whereas specific heat $c$ (see Bitz and Lipscomb, 1999, Eq. 1) and heat conductivity $k$ (Pringle et al., 2007) depend on $S$ and $T$; both vary significantly over the typical temperature range. In turn, the sea ice heat diffusivity decreases by an order of magnitude from $-15^{\circ} \mathrm{C}$ to the vicinity of the freezing point (see Fig. 1d). One major issue with this formulation of $k$ is that $c$ and $k$ have uncontrolled asymptotic properties. In particular, $k$ is expected to decrease rapidly near the ice bulk melting temperature, which is not the case in the observation-derived Pringle et al. fit. In turn, whereas $k$ should converge to the thermal diffusivity of salt water, the computed 20 $K$ instead sharply decreases, approaching $10^{-9} \mathrm{~m}^{2} \mathrm{~s}^{-1}$.

A third option for the choice of the representative thermal diffusivity is that of pure ice, based on the assumption that the surrounding sea ice does not maintain phase equilibrium with the moving brine. Finally, one could also use a hybrid diffusivity, based on the heat conductivity of pure ice and the specific heat and density of the moving brine. Such relationship is obtained from a direct scaling of the advective and diffusive terms in the mushy-layer heat equation. For our analysis, we here only retain the first two options, which span the entire range of possible choices of thermal diffusivity

Rayleigh Number

M. Vancoppenolle et al.

Title Page

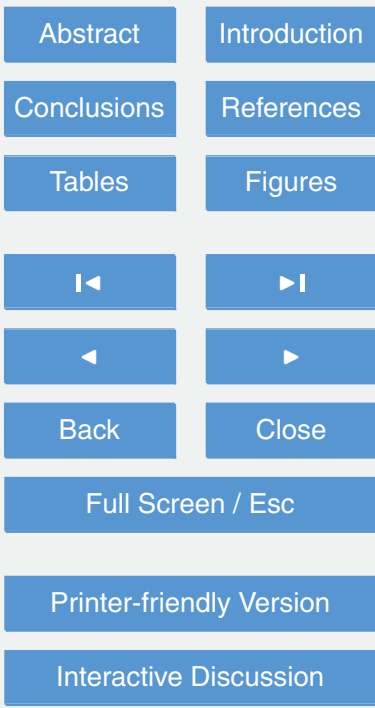

Interactive Discussion 


\subsection{Dynamic viscosity $\mu$}

The dynamic viscosity of sea water varies greatly with temperature and, slightly less so, with salinity. Again, data are very sparse below $0^{\circ} \mathrm{C}$. At $0^{\circ} \mathrm{C}$, dynamic viscosity of sea water with $S=34 \mathrm{~g} \mathrm{~kg}^{-1}$ is $1.9 \times 10^{-3} \mathrm{~kg}\left(\mathrm{~ms}^{-1}\right)^{-1}$ (Sharqawy et al., 2010, Eq. (22)).

5 At lower temperatures and higher salinity, this value increases, and an extrapolation of existing equations to brine at $T=-6^{\circ} \mathrm{C}$ and $S=100 \mathrm{~g} \mathrm{~kg}^{-1}$ gives a value of $2.5 \times$ $10^{-3} \mathrm{~kg}\left(\mathrm{~m} \mathrm{~s}^{-1}\right)^{-1}$, which is the value used in this note. Note that sometimes, kinematic viscosity $v$ is used in formulations of the Rayleigh number, which is simply $\mu \times \rho$.

\section{Impact of the different physical parameterizations on the Rayleigh number}

10 As detailed in the previous section, there are several possibilities regarding the choice of physical parameters used to compute $R$. We recommend the use of the original set of parameters proposed by Notz and Worster, as (i) this set was used to interpret the results of their experiments, (ii) using another set of parameters does not change the conclusions that can be drawn, as illustrated in the forthcoming paragraphs.

To illustrate the impact of physical uncertainties, we computed $R a$ using three sets of physical parameters (see Table 1). The NW08 set correspond to the original Notz and Worster (2008) computation. The second set (NW-E) is the same as NW08 except that the Eicken et al. $\Pi$ is used instead of Freitag's. The LIM set of parameters is the one used in the LIM1D model (Vancoppenolle et al., 2010) and includes simplifications for $S_{\mathrm{br}}, e$, Freitag's $\Pi$ and the sea ice diffusivity. These computations were based on vertical profiles of $S$ and $T$ from 31 ice cores from the Circumpolar Flaw Lead (CFL) study in the Beaufort Sea, covering an almost entire sea ice season, from December 2007 to June 2008. More information on the physical settings is given in Carnat et al. (2013). The computed vertical profiles of $R a$ are shown for three cores, characteristic of fall, winter and spring seasons (Fig. 2), as well as the full time series of the vertically-averaged $R a$ (Fig. 3).
Rayleigh Number

M. Vancoppenolle et al.

Title Page

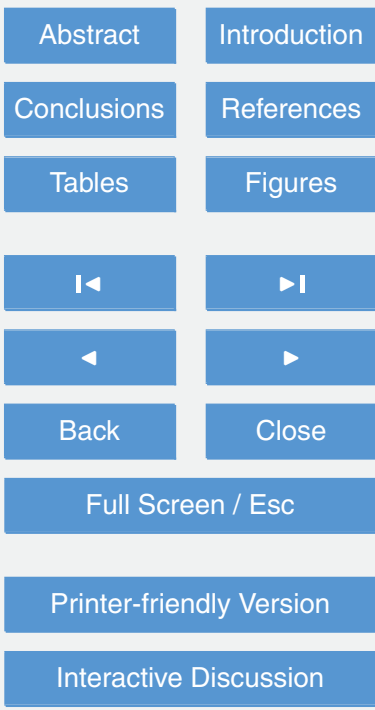

Interactive Discussion 
We first note that the different formulations used give significantly different results. $R a$ computed using NW08 and LIM are generally close, with small differences essentially due to different $k$. The large $S_{\text {br }}$ differences in NW08 and LIM have a small impact on $R a$, because they occur below $T=-5^{\circ} \mathrm{C}$, which also drastically reduces $\Pi$. In contrast, 5 using the permeability of Eicken et al. induces a 2-fold mean increase in $R$ a compared to NW08, especially strong at high $T$, inducing large differences in $\Pi$. Despite these differences, the shape of the seasonal cycle of the mean is similar for all formulations, with maxima in fall and spring, essentially driven by relatively high temperatures. The vertical shape of $R a$ profiles is also similar among different formulations for every of 10 the three typical ice regimes found in the data set (fall, winter-early spring, late spring) as illustrated in Fig. 2 (see also Carnat et al., 2013).

\section{Observation and sampling errors}

Measurements of ice-core temperature and bulk salinity include observation errors that affect the calculation of the Rayleigh number. In particular, the bulk salinity is un5 derestimated due to brine losses during core extraction in warm and/or high salinity sections, where liquid fraction, permeability and Rayleigh number are highest (Eicken et al., 1991; Notz et al., 2005). For cold ice with low permeability, the sampling error in bulk salinity should be of a few tenths of $\mathrm{g} \mathrm{kg}^{-1}$ at most. However, near the ice base, where the temperature is close to the freezing point and permeability is high, brine 20 loss implies an underestimation of the bulk salinity ranging up to $20 \mathrm{~g} \mathrm{~kg}^{-1}$ compared to non-destructive measurements (Notz et al., 2005). In order to illustrate the impact of salt loss during coring on the Rayleigh number, we added a synthetic correction $\Delta S$ to the measured bulk salinity profile, designed for illustrative purposes. $\Delta S$ depends on porosity. It starts from zero at $e=0$, quickly increases from $e=4 \%$ on, reaches ing $40 \%$ at $e=20 \%$. The corrected bulk-salinity profiles are shown in gray in Fig. 2 ing $40 \%$ at $e=20 \%$. The corrected bulk-salinity profiles are shown in gray in Fig. 2 (upper panels). The impact of salt loss on the Rayleigh number is illustrated in the

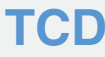

7, 3209-3230, 2013

Rayleigh Number

M. Vancoppenolle et al.

Title Page

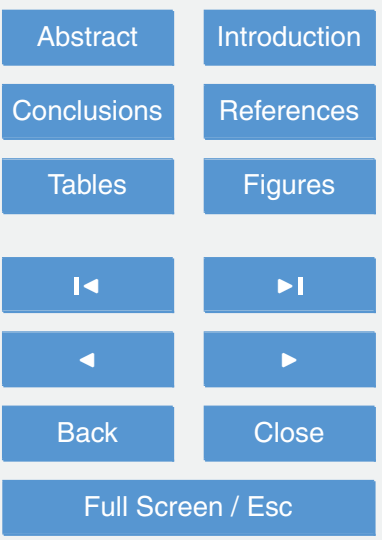

Printer-friendly Version

Interactive Discussion 
lower panels by the black (no correction) and gray (correction) curves. For the typical winter profile shown in Fig. $2 \mathrm{~b}$, e, an average salt loss of about $0.3 \mathrm{~g} \mathrm{~kg}^{-1}$ induces a 0.5 underestimation of the Rayleigh number. At the ice base, the salt loss introduced by the correction is maximum $\left(4.8 \mathrm{~g} \mathrm{~kg}^{-1}\right)$, and accounting for it increases the Rayleigh num5 ber by 2.7. This type of error virtually removes any evidence for the actively convective layer that is expected near the ice base.

A representative estimate of Rayleigh number profiles in sea ice is also hindered by the usually low ice core sampling rates, which only gives a snapshot of variables that are highly space and time dependent. Temperature strongly varies at sub-daily 10 and synoptic time scales. For illustration, a second series of $R a$ computations were done based on high-frequency $T$ and 5 ice-core $S$ profiles from the last 25 days of the Year-Round Ocean-Sea Ice Atmosphere Exchanges (YROSIAE) study on landfast sea ice in the Ross Sea (December 2011-December 2012). More information on the physical settings at YROSIAE will be given in forthcoming papers. The specificity of this 15 data set compared to the previous one is the presence of $I c e-T$, an automated sea ice buoy recording $T$ at high frequency $(15 \mathrm{~min}$ ) every $5-12.5 \mathrm{~cm}$ depth. $I c e-T$ records indicate ample $T$ diurnal differences up to $>5^{\circ} \mathrm{C}$ near the ice surface from early November (day 300) onwards (Fig. 4, upper panel). The large temperature range is due to thin snow (a few cm, typical of coastal wind-blown Antarctic fast ice), e.g., too small to provide efficient thermal insulation and protection from sunlight penetration. Subsequent $R a$ diurnal oscillations, reaching $\sim 3$ with the NW-08 formulation (Fig. 4, lower panel), follow temperature forcing once the ice is warm and permeable enough (daily mean $T \gtrsim-5^{\circ} \mathrm{C}$, from day 320 ). Ra diurnal cycle is strongest near the ice surface and is likely larger than estimated with NW-08 due to salt loss during coring (see NW- $\Delta S$ curves in Fig. 4). Possible high-frequency $S$ variations have not yet been measured. 1$D$ model simulations of sea ice desalination indicate that super-critical Ra values, built up over several days, quickly ( $<1-3$ days) vanish during full-depth convective events rapidly expelling salt out of sea ice (Vancoppenolle et al., 2010; Jardon et al., 2013). 
Large spatial variations in all sea ice variables from centimetric to kilometric scales are also important, and this is particularly true for $S$ and $T$, and hence, $R$ a. Horizontal variations in bulk salinity, related to the presence or absence of brine channels occur at $\mathrm{cm}$ scales (Cottier et al., 1999; Gough et al., 2012). At larger-scale, snow-depth $5 \quad(0-100 \mathrm{~cm})$ and ice thickness $(0-20 \mathrm{~m})$ can widely vary mostly due to blowing snow (Massom et al., 2001) and ice deformation (Thorndike et al., 1975), respectively, which clearly affects $T$ (Perovich et al., 2003) and $S$ (Eicken et al., 1991). But these spatial variations rather affect the large-scale representativeness of $R a$ estimations rather than their actual intrinsic validity.

\section{Discussion}

We have shown that the various uncertainties in the physical parameters, observational errors, and sampling issues make comparisons of Ra numbers derived from ice core data against any observational threshold imprecise. Errors in $R a$ are the largest for warm and permeable ice. Uncertainties in permeability, in particular, have a large 15 impact on $R$ a. Weekly ice core sampling does not resolve significant diurnal variations in $R a$ that could only be identified from high-frequency vertical $T$. In this context, it seems difficult to draw firm conclusions on brine convection from the comparison of $R a$ with any observational threshold (e.g. 7; Notz and Worster, 2008), a threshold that is currently not well constrained either.

20 In contrast, the shape of the vertical $R a$ profiles, as well as the seasonality of the mean, are only slightly affected by errors and parameterization uncertainties. Hence, relative comparisons can be made, such as brine convective activity is likely more intense in spring than in deep winter, or in winter, the ice is more prone to convection at the base than at the top. While firm statements are not solid at this stage, $R$ a still geochemical tracer concentrations in sea ice, upper ocean salinity, ...). An important caution is the relatively weak evidence for the basal winter permeable and convective

Rayleigh Number

M. Vancoppenolle et al.

Title Page

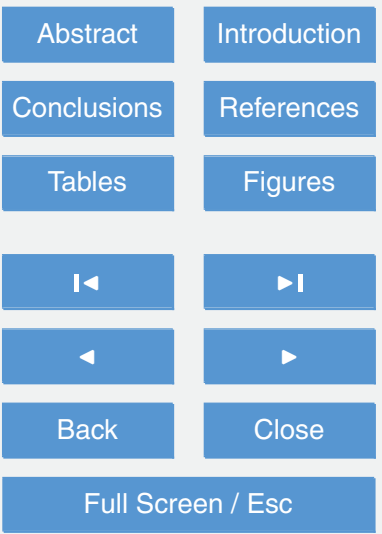

Printer-friendly Version

Interactive Discussion 
layer for all parameterizations, which can be related to salt loss during ice coring. As all parameterizations lead to similar conclusions, we advise to use the original Notz and Worster $R$ a formulation, for consistency with previous work (see Table 2).

A qualitative evaluation of $\mathrm{Ra}$ profiles derived from the CFL ice core data indicates 5 that although convection mostly occurs near the ice base during winter, full depth brine circulation is possible in thin growing ice and in spring, when rising temperatures make the ice more permeable (see Figs. 3 and 4), as argued by Jardon et al. (2013). The latter type of brine convection could exhibit diurnal variations.

A more quantitative analysis of some of the uncertainties described in this paper 10 is currently hindered by a lack of sufficient experimental data. In particular, a better description of brine properties at low temperatures, a better understanding of the evolution of sea-ice permeability, and a more robust quantification of systematic biases related to ice-core studies are very desirable. We hope that the review of the current state of our understanding as summarized by this study will be helpful in guiding such 15 future work.

Acknowledgements. This paper was written thanks to: BISICLO, funded through the 7th research program of European Union (FP7/PEOPLE-2012-CIG); YROSIAE (FNRS-FRFC contract 2.4649.07); BIGSOUTH (Belgian Science Federal Policy Office). The development and deployment of the Ice-T buoy are supported by ANR and IPEV through the OPTIMISM 20 project (ANR-09- BLAN-0227-01; IPEV 1015). Many thanks to G. Ivan , H. Duhibou and F. Brabic for hintful suggestions.

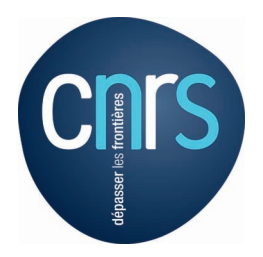

The publication of this article is financed by CNRS-INSU.

Title Page

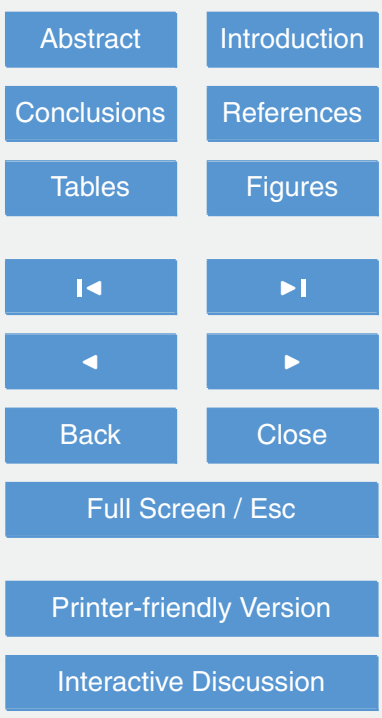




\section{References}

Assur, A.: Composition of sea ice and its tensile strength, A. Nat. Acad. Sci./Nat. Res. Council, Arctic Sea Ice, 598, 106-138, 1958. 3213

Bitz, C. M. and Lipscomb, W. H.: An energy-conserving thermodynamic model of sea ice, J. Geophys. Res., 104, 15669-15677, 1999. 3216

Carnat, G., Papakyriakou, T., Geilfus, N.-X., Brabant, F., Delille, B., Vancoppenolle, M., Gilson, G., Zhou, J., and Tison, J.-L.: "Investigations on Arctic first-year sea ice physical and textural properties in the Amundsen Gulf, November 2007 until June 2008", J. Glaciol., 12J148R, in press, 2013. 3211, 3217, 3218, 3228, 3229

Cottier, F., Eicken, H., and Wadhams, P.: Linkages between salinity and brine channel distribution in young sea ice, J. Geophys. Res., 104, 15859-15871, 1999. 3220

Eicken, H., Lange, M. A., and Dieckmann, G. S.: Spatial variability of sea ice properties in the northwestern Weddell Sea, J. Geophys. Res., 96, 10603-10615, 1991. 3218, 3220

Eicken, H., Grenfell, T. C., Perovich, D. K., Richter-Menge, J. A., and Frey, K.: Hydraulic controls of summer Arctic pack ice albedo, J. Geophys. Res., 109, C08007, doi:10.1029/2003JC001989, 2004. 3215, 3217, 3218, 3225, 3227

Freitag, J.: Untersuchungen zur Hydrologie des arktischen Meereises-Konsequenzen für den kleinskaligen Stofftransport, Ber. Polarforsch., 325, 150 pp., 1999 (in German). 3214, 3215, 3217, 3225, 3227

20

Golden, K. M., Ackley, S. F., and Lytle, V. I.: The percolation phase transition in sea ice, Science, 282, 2238-2241, 1998. 3215

Gough, A., Mahoney, A., Williams, P. L. M., and Haskell, T.: Sea ice salinity and structure: A winter time series of salinity and its distribution, J. Geophys. Res., 117, C03008., doi:10.1029/2011JC007527, 2012. 3220

Griewank, P. and Notz, D.: Insights into brine dynamics and sea-ice desalination from a 1-D model study of gravity drainage, J. Geophys. Res., doi:10.1002/jgrc.20247, 2013. 3211, 3216

IOC, SCOR, and IAPSO: The international thermodynamic equation of seawater - 2010: Calculation and use of thermodynamic properties, Intergovernmental Oceanographic Commission,
7, 3209-3230, 2013

Rayleigh Number

M. Vancoppenolle et al.

Title Page

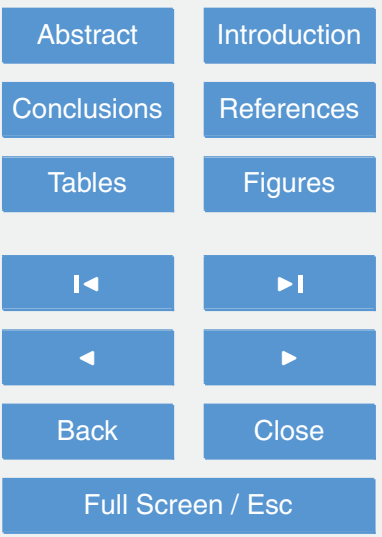

Printer-friendly Version

Interactive Discussion 
Jardon, F. P., Vivier, F., Vancoppenolle, M., Lourenço, A., Bouruet-Aubertot, P., and Cuypers, Y.: Full-depth desalination of warm sea ice, J. Geophys. Res.-Oceans, 118, 435-447, doi:10.1029/2012JC007962, 2013. 3211, 3219, 3221

Massom, R. A., Eicken, H., Haas, C., Jeffries, M. O., Drinkwater, M. R., Sturm, M., Worby, A. P.,

$5 \quad$ Wu, X., Lytle, V. I., Ushio, S., Morris, K., Reid, P. A., Warren, S. G., and Allison, I.: Snow on Antarctic sea ice, Rev. Geophys., 39, 413-445, 2001. 3220

McDougall, T. and Barker, P.: Getting started with TEOS-10 and the Gibbs Seawater (GSW) Oceanographic Toolbox, Tech. rep., SCOR/IAPSO WG27, 2011. 3213

Notz, D.: Thermodynamic and fluid-dynamical processes in sea ice, Ph. D. thesis, University of Cambridge, 2005. 3213, 3214

Notz, D. and Worster, M. G.: In situ measurements of the evolution of young sea ice, J. Geophys. Res., 113, C03001, doi:10.1029/2007JC004333, 2008. 3211, 3215, 3217, 3220, 3221, 3226

Notz, D. and Worster, M. G.: Desalination processes in sea ice, J. Geophys. Res., 114, C05006, doi:10.1029/2008JC004885, 2009. 3210

15 Notz, D., Wettlaufer, J. S., and Worster, M. G.: A non-destructive method for measuring the salinity and solid fraction of growing sea ice in situ, J. Glaciol., 51, 159-166, 2005. 3218

Perovich, D. K., Grenfell, T. C., Richter-Menge, J. A., Light, B., Tucker III, W. B., and Eicken, H.: Thin and thinner: Sea ice mass balance measurements during SHEBA, J. Geophys. Res., 108, 8050, doi:10.1029/2001JC001079, 2003. 3220

20 Pounder, E. R.: The Physics of Ice, Pergamon Press, Oxford, UK, 1965. 3214

Pringle, D. J., Eicken, H., Trodahl, H. J., and Backstrom, L.: Thermal conductivity of landfast Antarctic and Arctic sea ice, J. Geophys. Res., 112, C04017, doi:10.1029/2006JC003641, 2007. 3216

Rees Jones, D. W., and Worster, M. G.: A simple dynamical model for gravity drainage of 25 brine from growing sea ice, Geophys. Res. Lett., 40, 307-311, doi:10.1029/2012GL054301, 2013a. 3211

Rees Jones, D. W. and Worster, M. G.: Fluxes through steady chimneys in a mushy layer during binary alloy solidification, J. Fluid Mech., 714, 127-151, 2013b. 3211

Sharqawy, M. H., Lienhard V, J. H., and Zubair, S. M.: Thermophysical properties of seawater: a review of existing correlations and data, Desalination and Water Treatment, 16, 354-380, 2010. 3215, 3217

Thomas, D. N. and Dieckmann, G. (Eds.): Sea Ice (2nd edn.), Wiley-Blackwell, 2010. 3210 
Thorndike, A. S., Rothrock, D. A., Maykut, G. A., and Colony, R.: The thickness distribution of sea ice, J. Geophys. Res., 80, 4501-4513, 1975. 3220

Untersteiner, N.: Natural desalination and equilibrium salinity profile of perennial sea ice, J. Geophys. Res., 73, 1251-1257, 1968. 3210

5 Vancoppenolle, M., Goosse, H., de Montety, A., Fichefet, T., Tremblay, B., and Tison, J.-L.: Modeling brine and nutrient dynamics in Antarctic sea ice: the case of dissolved silica, J. Geophys. Res., 115, C02005, doi:10.1029/2009JC005369, 2010. 3211, 3216, 3217, 3219

Wells, A. J., Wettlaufer, J. S., and Orszag, S. A.: Maximal potential energy transport: a variational principle for solidification problems, Phys. Rev. Letters, 105, 254502, doi:10.1103/PhysRevLett.105.254502, 2010. 3211

Wells, A. J., Wettlaufer, J. S., and Orszag, S. A.: Brine fluxes from growing sea ice, Geophys. Res. Lett., 38, L04501, doi:10.1029/2010GL046288, 2011. 3211

Wettlaufer, J. S., Worster, M. G., and Huppert, H. E.: The phase evolution of young sea ice, Geophys. Res. Lett., 24, 1251-1254, 1997. 3215

Zhou, J., Delille, B., Eicken, H., Vancoppenolle, M., Brabant, F., Carnat, G., Geilfus, N.-X., Papakyriakou, T., and Tison, J.-L.: Physical and biogeochemical properties in landfast sea ice (Barrow, Alaska): insights on brine and gas dynamics across seasons, J. Geophys. Res., 118, 1-18, doi:10.1002/jgrc.20232, 2013. 3211

\section{Rayleigh Number}

M. Vancoppenolle et al.

Title Page

Abstract

Conclusions

Tables

14

4

Back
Introduction

References

Figures

$\Delta \mathbf{I}$

$>$

Close

Full Screen / Esc

Printer-friendly Version

Interactive Discussion 
Table 1. The sets of physical parameterizations used to compute $R a . \Delta S$ refers to the correction on ice salinity.

\begin{tabular}{llllll}
\hline Set & $S_{\text {br }}$ & $e$ & $\Pi$ & $\kappa$ & $\Delta S$ \\
\hline NW08 & 3-order (Eq. 4) & full (Eq. 6) & Freitag (1999) (Eq. 8) & brine & no \\
NW-E & 3-order (Eq. 4) & full (Eq. 6) & Eicken et al. (2004) (Eq. 9) & brine & no \\
LIM & linear fit (Eq. 5) & simple (Eq. 7) & Freitag (1999) (Eq. 8) & sea ice & no \\
NW- $\Delta S$ & 3-order (Eq. 4) & full (Eq. 6) & Freitag (1999) (Eq. 8) & brine & yes \\
\hline
\end{tabular}

Rayleigh Number

M. Vancoppenolle et al.

Title Page

Abstract

Conclusions

Tables

14

4

Back

Introduction

References

Figures

$>1$

Close

Full Screen / Esc

Printer-friendly Version

Interactive Discussion 
Table 2. Recommended set of parameters for the computation of the Rayleigh number $R a=$ $\frac{g \Delta \rho z \Pi}{\kappa \mu}$, following Notz and Worster (2008).

\begin{tabular}{lll}
\hline Quantity & Symbol & Parameterization \\
\hline Acceleration of gravity & $g$ & $9.81 \mathrm{~ms}^{-2}$ \\
Brine-seawater density difference & $\Delta \rho$ & Eq. (3), with $B=0.81 \mathrm{~kg} \mathrm{~m}^{-2}\left(\mathrm{~g} \mathrm{~kg}^{-1}\right)^{-1}$ \\
& & and $S^{\text {br }}$ from Eq. (4) \\
Permeability & $\Pi$ & Eq. (8), with $e$ from Eq. (6) \\
Thermal diffusivity of brine & $\kappa$ & $1.2 \times 10^{-7} \mathrm{~m}^{2} \mathrm{~s}^{-1}$ \\
Dynamic viscosity of brine & $\mu$ & $2.5 \times 10^{-3} \mathrm{~kg}(\mathrm{~ms})^{-1}$ \\
\hline
\end{tabular}

7, 3209-3230, 2013

Rayleigh Number

M. Vancoppenolle et al.

Title Page

Abstract

Introduction

Conclusions

References

Tables

Figures

14

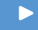

$<$

Back

Full Screen / Esc

Printer-friendly Version

Interactive Discussion 

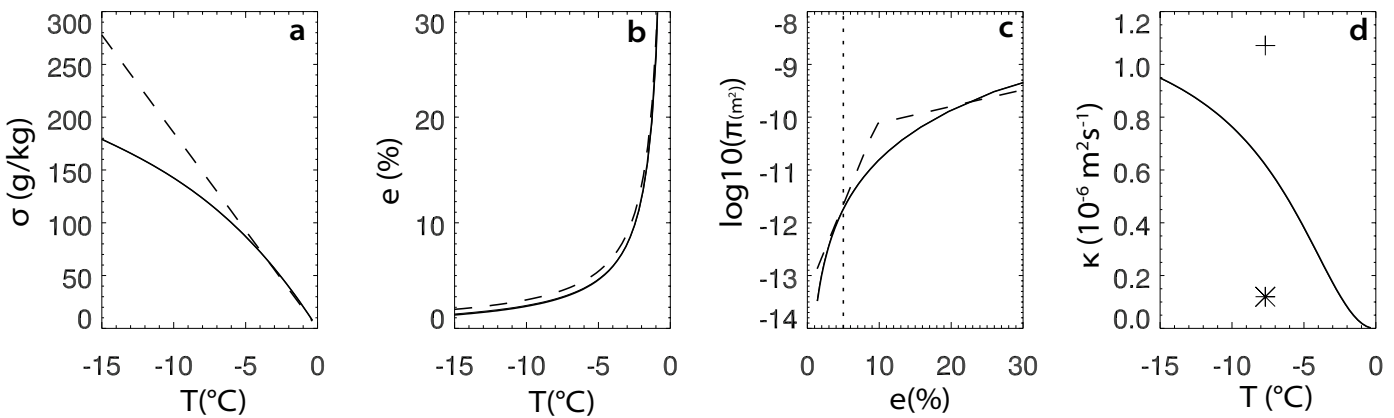

Fig. 1. (a) Brine salinity $S_{\text {br }}(T)$ from 3-order (Eq. 4, solid) and linear expressions (Eq. 5, dash); (b) liquid fraction $e(T)$ from exact (Eq. (6), solid) and linear expressions (Eq. 7, dash), using $S=5 \mathrm{~g} \mathrm{~kg}^{-1}$; (c) sea ice permeability shown as $\log _{10}[\Pi(e)]$ from Freitag (1999) (Eq. 8, solid) and Eicken et al. (2004) (Eq. 9, dash) with the $5 \%$ e threshold (dots); (d) sea ice thermal diffusivity used in LIM1D, computed using $S=5 \mathrm{~g} \mathrm{~kg}^{-1}$, as well as pure ice (+) and brine $(*)$ values at $0^{\circ} \mathrm{C}$.

7, 3209-3230, 2013

Rayleigh Number

M. Vancoppenolle et al.

Title Page

Abstract

Introduction

Conclusions

References

Tables

Figures

TCD

Tables

14

Back

Close

Full Screen / Esc

Printer-friendly Version

Interactive Discussion 


\section{$\mathrm{T}\left({ }^{\circ} \mathrm{C}\right)$}
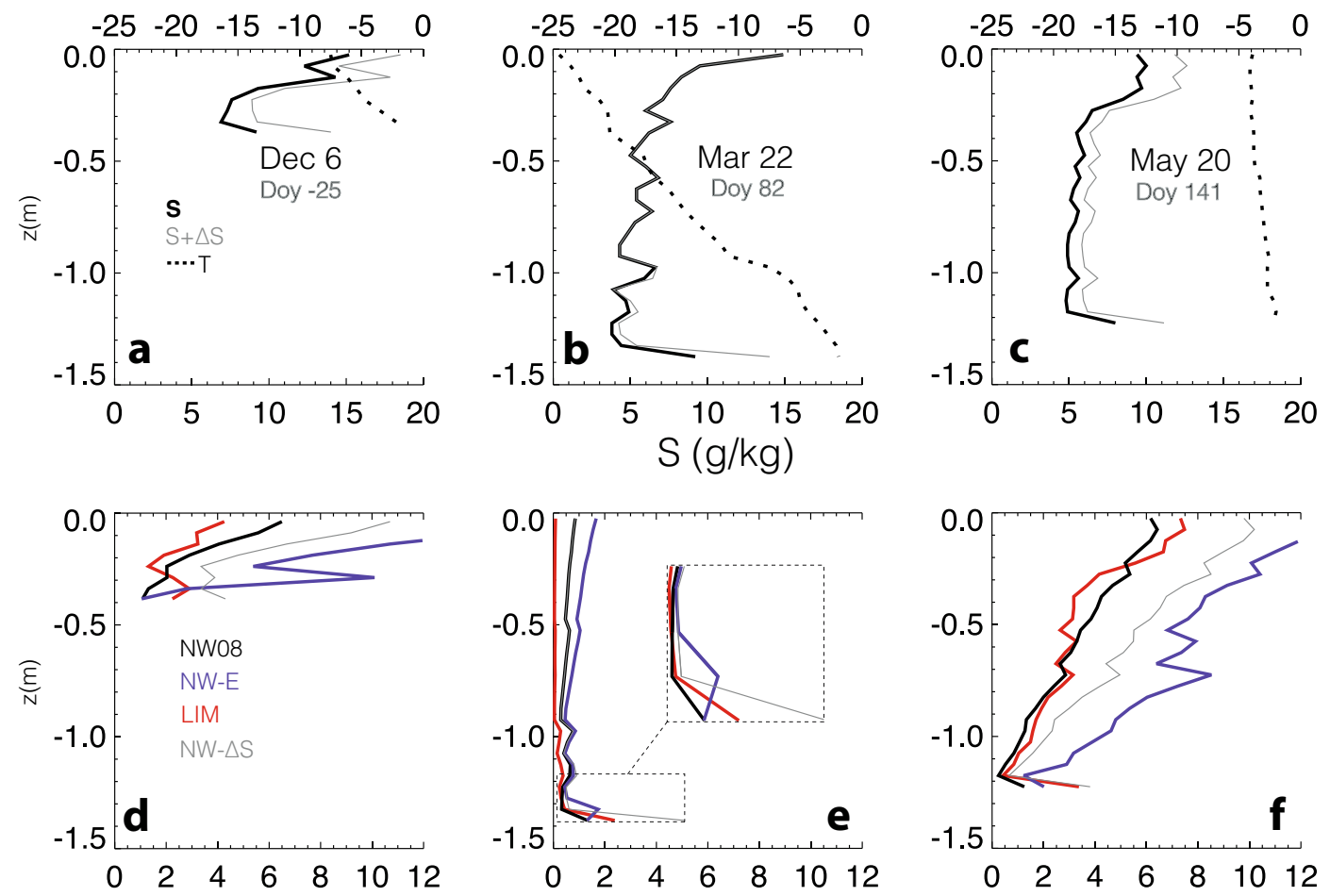
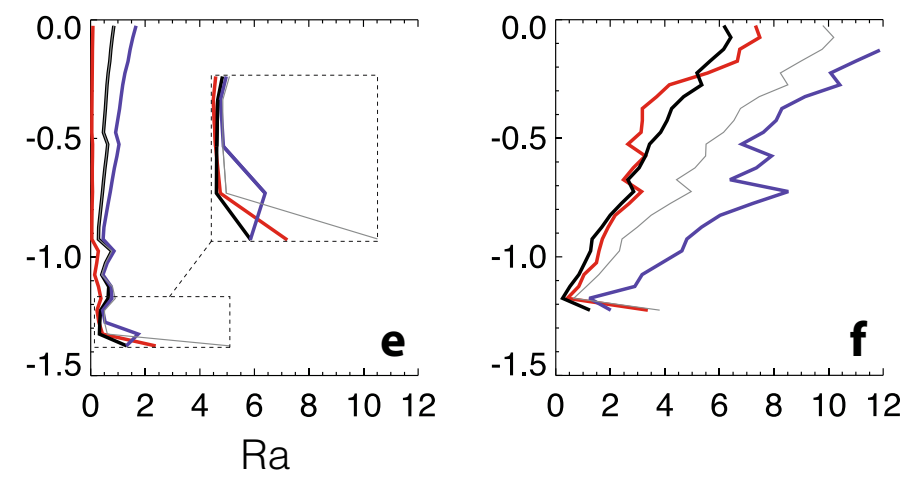

TCD

7, 3209-3230, 2013

Rayleigh Number

M. Vancoppenolle et al.

Title Page

Abstract

Introduction

Conclusions

References

Tables

Figures

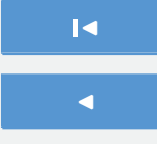

$\Delta$

Back

Close

Full Screen / Esc

Printer-friendly Version

Interactive Discussion

spring): (top) $S$ (solid black) $S+\Delta S$ (e gimes of ice growth (fall, winter/early spring, and late (bottom) Ra computed with each parameter set (see Table 1). Data from the CFL study in the Beaufort Sea, 2007-2008 (Carnat et al., 2013). 


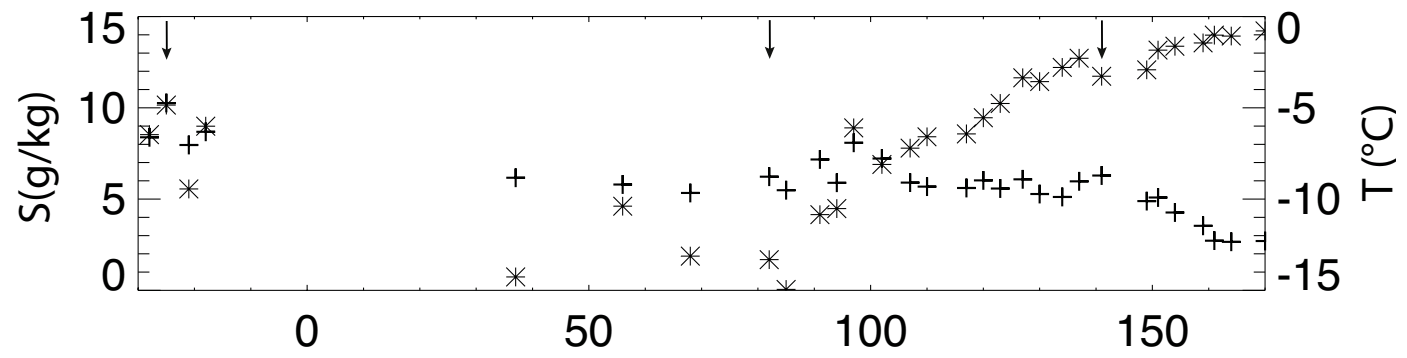

7, 3209-3230, 2013

Rayleigh Number

M. Vancoppenolle et al.

Title Page

Abstract

Introduction

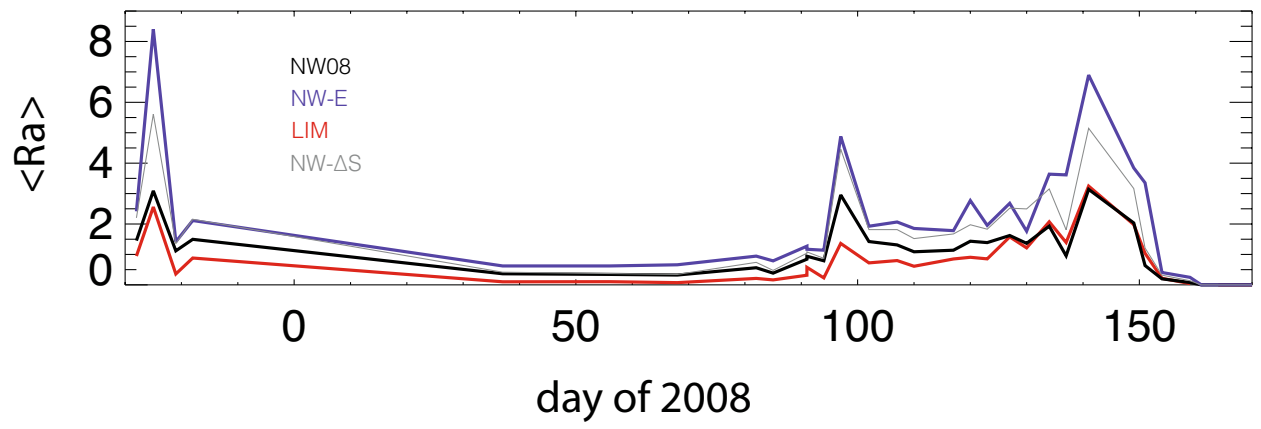

Conclusions

References

Tables

Figures

14

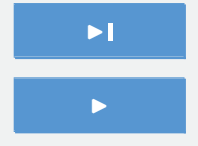

4

Back

Close

Full Screen / Esc

Printer-friendly Version

Fig. 3. Time series of vertically-averaged $S(+)$ and $T\left({ }^{*}\right)$ (top); and vertically-averaged $R a$, computed with each parameter set (see Table 1 for details) (bottom). Based on data from the CFL study in the Beaufort Sea, 2007-2008 (Carnat et al., 2013). Arrows indicate stations depicted in Fig. 2.

Interactive Discussion 

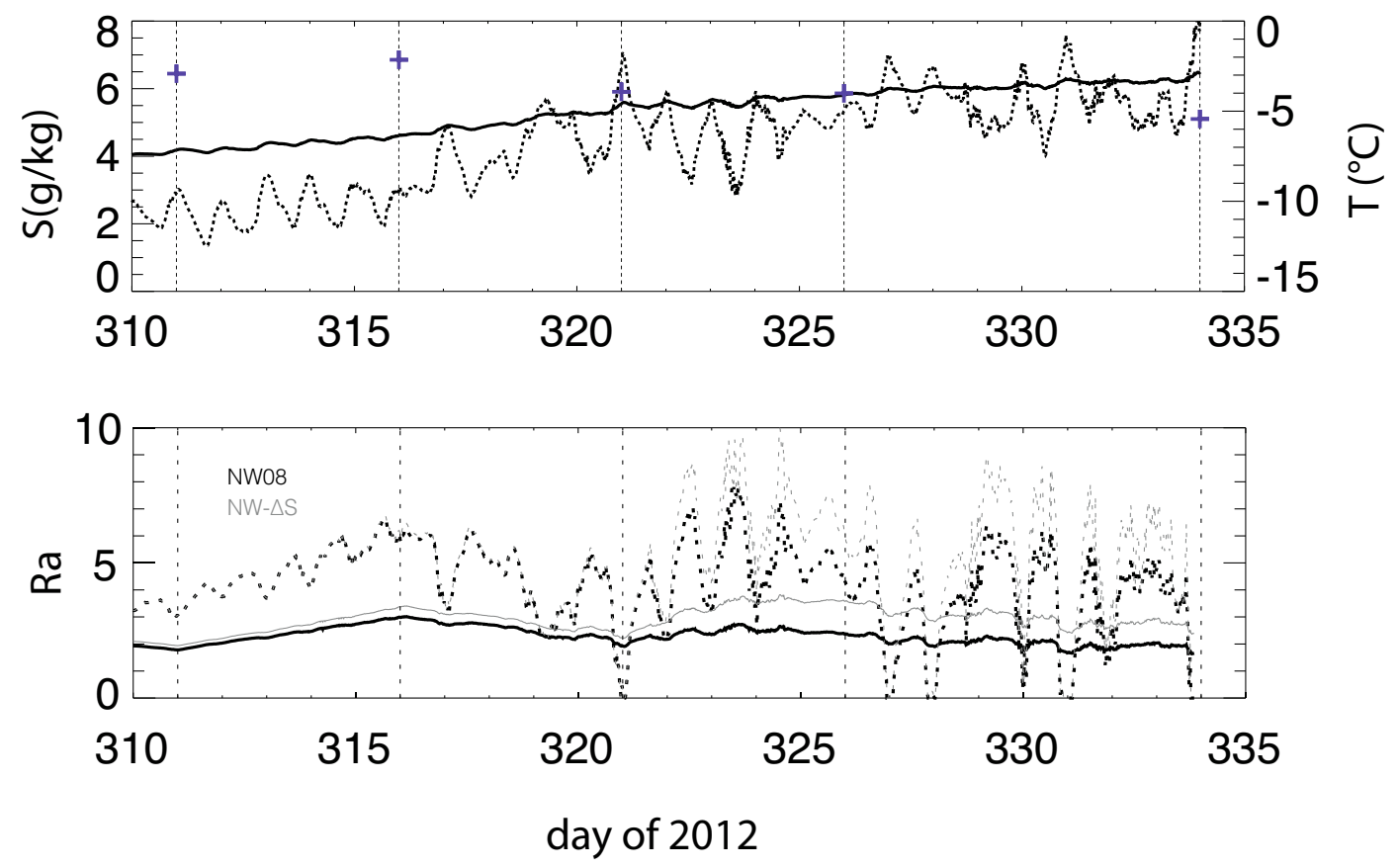

Title Page

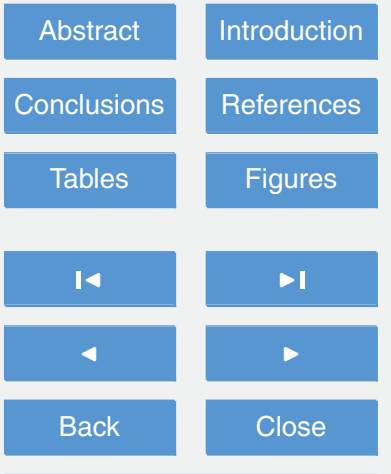

Full Screen / Esc

Fig. 4. Time series of vertically-averaged $S(+)$, vertically-averaged $T$ (solid); and upper-layer $T$ (dash) (top); and of vertically-averaged (solid) and upper-layer (dash) $R a$, computed with the NW-08 (black) and NW- $\Delta S$ (grey) parameter sets (see Table 1 for details) (bottom). Results for only NW-08 and NW- $\Delta S$ are shown because computations from LIM and NW-E are similar to the CFL results. Based on data from the YROSIAE study in the landfast sea ice zone of the Ross Sea, 2012. 